\title{
SENTIDOS E COTORNOS DA INOVAÇÃO NA EDUCAÇÃO
}

\author{
A. NOGARO* e C. BATTESTIN \\ Universidade Regional Integrada do Alto Uruguai e das Missões (URI) \\ narnaldo@uri.edu.br*
}

Artigo submetido em dezembro/2015 e aceito em março/2016

DOI: $10.15628 /$ holos.2016.3097

\section{RESUMO}

O presente artigo é resultante de uma investigação bibliográfica sobre o tema inovação e sua relação com a educação. O mesmo tem como objetivo debater os possíveis sentidos e conotações do conceito "inovação" na prática educativa, bem como, as diferentes abordagens teóricas feitas, sem analisar o seu verdadeiro significado. Seria a inovação o mesmo que novidade? Mudança? Novas tecnologias? Novo paradigma?
Certamente existe a necessidade de analisar o contexto histórico e social para não cairmos na divagação, inconsistência, e incoerência de sentidos e ausência de clareza sobre a significação e representação do conceito. Só assim, poderemos ressaltar os sentidos e contornos que a inovação apresenta para dialogarmos com o mundo da educação.

PALAVRAS-CHAVE: inovação, educação, mudança.

\section{SENSES AND OUTLINES OF INNOVATION IN EDUCATION}

\begin{abstract}
This article is the result of a bibliographical research about innovation and its relationship with education. It aims to discuss the possible meanings and connotations of the concept of "innovation" in the educational practice as well as the different theoretical approaches made, without analyzing its true meaning. Would innovation be the same as novelty? Change? New technologies? New
\end{abstract}

paradigm? There is certainly a need to analyze the social and historical context not to fall into divagation, inconsistency and incoherence of meanings and lack of clarity about the signification and representation of the concept. Only then can we highlight the meanings and outlines that the innovation presents so to debate with the world of education.

KEYWORDS: innovation, education, change. 


\section{APRESENTAÇÃO}

A gênese do texto traz o questionamento a respeito do que se tem entendido sobre inovação, ao longo do mesmo apresenta-se compreensões de autores sobre o tema em pauta, problematizando-as. Por fim, apontam-se considerações e ideias que caracterizam uma educação, escola ou prática educativa inovadora, para que sirva de referência a quem desejar caminhar nesta direção.

Por que tratar da inovação na educação? Por que apesar de passadas algumas décadas que marcaram o seu aparecimento como discurso, ela continua ocupando o centro na discussão educacional. O que queremos dizer quando nos referimos à inovação? O que é inovar a educação? Uma prática inovadora? E uma prática educativa inovadora? Principiamos a escrita deste texto com a elaboração de um estado do conhecimento para averiguar o que há de produzido em termos de livros ou artigos científicos sobre o assunto "inovação na educação" e "educação inovadora". Deparamo-nos com uma pluralidade de visões e entendimentos sobre o mesmo, o que não nos desencoraja de reunirmos aqui alguns deles e construirmos o nosso. Ousamos também transformar este texto em um espaço para promover a possibilidade do pensar e do fazer reflexivos, em que as "inovações" tenham a oportunidade de apresentar-se, contradizer-se e transformar-se.

Ao tratarmos da inovação na educação vamos nos esforçar para expor nossos argumentos com clareza para que não sejamos mal interpretados ou taxados como intransigentes, retrógrados ou contrários à inovação, por pretender um discurso crítico sobre este tema. Ao longo do texto nos posicionaremos de maneira efetiva sobre o tema, mas é na segunda parte do mesmo que apontaremos alternativas possíveis para uma prática educativa inovadora, não como receita, mas como marco teórico-conceitual que possa subsidiar e dar luz ao caminho da inovação.

Querer adivinhar ou pensar o futuro é possível como exercício mental de ficção ou divagação, no entanto, quando se trata de abordar questões concretas que afetam o cotidiano como a inovação pedagógica, exige que tenhamos os dois pés no chão. Logo, falaremos do futuro a partir do presente ou das possibilidades que vislumbramos. Não nos é possível pensar em algo surreal transpondo-nos ao vivido em que nos encontramos, não ao menos enquanto falamos de educação, ela é sempre situada, sua realidade nos acorda e nos interpela.

Desta forma, não há impedimento que desejemos ou imaginemos possibilidades, sonhemos, mas não podemos esquecer que elas sempre carregam as marcas do presente, estão profundamente arraigadas à nossa condição e ao nosso contexto. Na imaginação ou em filmes de ficção podemos regredir ou avançar no tempo, mas aquilo que estamos tratando exige a máxima lucidez. Como horizonte a utopia pode ser vislumbrada, o delírio não nos cabe.

A inovação abre espaço para a imaginação, para o pensamento criativo, para certa sanidade insana de querer transpor limites, ela não pactua com a venda de ilusões ou previsões descabidas.

\section{INOVAÇÃO: SENTIDOS POSSÍVEIS}

Constatamos que o conceito "inovação" é usado com diferentes sentidos e em alguns casos sem uma preocupação em precisá-lo. Não poucos textos apresentam a palavra "inovação" quando 
desejam adjetivar práticas ou processos educacionais com roupagens ou até conteúdos que se oponham a posições conservadoras. Em outros casos faz-se uso da "inovação" mais como estratégia para chamar a atenção, como marketing, para vender uma ideia ou produto, destacar uma instituição, do que existência de efetiva mudança ou diferença.

Aqui alertamos para uma estratégia que "vende" muito bem, chama atenção até aos menos atentos, e que tem sido muito empregada, o uso da expressão: "trata-se de algo inovador!" É sobre ela que precisamos lançar o olho crítico, perguntarmo-nos o que há por trás das aparências, qual sua essência?

Saviani (1980) apresenta quatro níveis de inovação na esfera educacional, segundo concepções filosóficas que as sustentam, ou seja, quando indagamos a respeito da inovação não podemos esquecer que uma concepção filosófica (entenda-se referência teórica) a orienta ${ }^{1}$. Para cada vertente de pensamento há um modus operandi próprio e uma finalidade para a educação.

a ) São mantidas intactas a instituição e as finalidades do ensino. Quanto aos métodos, são mantidos no essencial, sofrendo, no entanto, retoques superficiais.

$b$ ) São mantidas a instituição e as finalidades do ensino. Os métodos são substancialmente alterados.

c) São mantidas as finalidades do ensino. Para atingi-las, entretanto, a par das instituições e métodos convencionais, retocados ou não, utilizam-se formas parainstitucionais e/ou não-institucionalizadas.

d) A educação é alterada nas suas próprias finalidades. Buscam-se os meios considerados mais adequados e eficazes para se atingir as novas finalidades (SAVIANI, 1980, p. 26).

De acordo com Leite; Genro; Braga (2011), a inovação pedagógica em não sendo simples e intuitiva torna-se campo de disputa quando questiona pressupostos filosóficos, entre os quais a concepção do humano, de conhecimento e valores que constituem o ato educativo e a cientificidade do fazer docente.

Portanto, sempre cabem alguns questionamentos: Como o discurso da inovação chega à educação? Por quem ele é trazido? Com que sentido? O que desejamos ao aderi-lo ou não? Segundo Messina (2001) a inovação foi assumida como fim em si mesma e como solução para problemas educacionais estruturais e complexos. Como decorrência, em nome da inovação, têm-se legitimado propostas conservadoras, homogeneizado políticas e práticas e promovido a repetição de propostas que não consideraram a diversidade dos contextos sociais e culturais. Além disso, a categoria inovação foi tratada como algo a parte das teorias sobre a mudança educacional.

Sabemos que a ideia de inovação como tem sido concebida por muitos se origina no mundo da empresa, da produção, do espaço mercadológico onde inovar tem a ver com sobrevivência, com manter-se em sintonia com o desejo do cliente ou do consumidor. O conceito de Inovação já foi pensando por Adam Smith em meados do século XVIII, momento em que o mesmo analisou a relação existente entre a mudança da técnica moderna e o acúmulo de capital, ocasionando, a

\footnotetext{
1 Saviani (1980) faz referência às concepções "humanista" tradicional, "humanista" moderna, analítica e dialética. Segundo o autor a concepção dialética concebe para a educação o papel de colocar-se a serviço da nova formação social em gestação no seio da velha formação até então dominante. Aponta, pois, para um sentido radical de inovação, isto é, inovar significa mudar as raízes, as bases. Trata-se, pois, de uma concepção revolucionária de inovação.
} 
divisão de trabalho e competição. A partir destas análises, a inovação consistiu em um novo método de produção, abrindo espaço para o novo, gerando uma nova estrutura organizacional. Daí que há maior propensão de assumi-la ou identificá-la como técnica, o que a distanciaria de uma compreensão de educação cuja perspectiva é a formação do todo do sujeito (do alemão bildung).

A área da produção tecnológica é uma das mais salientes quando se fala em inovação, uma vez que nela percebe-se com maior nitidez a necessidade da inovação para não perecer. Inovar é contrapor-se ao obsoleto, ao ultrapassado, ao desuso. As novas tecnologias eletrônicas e digitais simbolizam com grande propriedade e são o exemplo fiel para ilustrar o que a inovação representa para o mundo do mercado, nele inovar é permanecer vivo, não inovar é sucumbir. Qual sentido se quer para a educação?

Ao longo da história humana em muitos momentos ocorreram situações muito similares às que presenciamos hoje com a ideia de "inovação". O que há de novo ou diferente? Inovar não se trata de inventar, mas de recriar, revestir com uma ideia não pensada até então, surpreender. Porém, temos que estar atentos aos subterfúgios que encobrem verdades, engambelam ou mascaram velhas práticas com roupagens novas. Será que não estamos guardando vinho novo em pipas velhas?

Novos argumentos com novas linguagens são sustentados para camuflar velhas ideologias que ameaçam o sentido comum do pessoal e do coletivo modernos.

Hoje o pensamento e as práticas conservadoras empregam roupagens teóricas ou científicas para empreender contrarreformas que querem refazer a história de sua forma, contando-a de outra maneira. Esquecem seu passado, reconstroem-no e, sem qualquer vergonha, nos anunciam um futuro esplendoroso (SACRISTÁN, 2015, p. 16).

No Brasil, há quem situe a gênese da inovação na educação na década de 1920-1930 com o aparecimento das ideias dos pioneiros da Educação Nova, no entanto, acreditamos que ela realmente toma feição em período mais próximo, nos anos sessenta. Messina (2007) afirma que desde os anos setenta, a mudança na educação é concebida como parte de um processo social de mudança acelerada. A caracterização da mudança social como o elemento distintivo da sociedade moderna e como eixo da modernização é o contexto no qual se insere qualquer alusão à necessidade e pertinência da mudança educacional.

Surge amparada no conceito de novidade. Não é o mesmo que reforma. Segundo Costa (2008), a inovação produz uma mudança de caráter singular e qualitativa das práticas educativas, originadas a nível micro, enquanto que a reforma corresponde a uma alteração introduzida no microssistema.

Inovação, é um termo usado frequentemente para designar alguma novidade. Quando esse dinamismo do "novo" ocorre, simultaneamente associamos que algo bom aconteceu ou está para acontecer. Etimologicamente, a palavra tem origem no latim, innovatio, significando renovação; todavia, o prefixo in encontrado no início da palavra assume a função de ingresso, ou seja, algo novo deverá acontecer, algo que não era feito antes, ou seja, uma novidade.

No entendimento de Cardoso (2007, p. 2) a inovação não se trata de uma mudança qualquer, ela tem um carácter intencional, afastando do seu campo "[...] as mudanças produzidas pela 
evolução 'natural' do sistema. A inovação é, pois, uma mudança deliberada e conscientemente assumida, visando uma melhoria da ação educativa". Também não é sinônimo de reforma, pois esta sempre resulta de um exercício de poder instituído de que dispõe o planificador e o legislador, gestada no exterior do ambiente onde deve ser aplicada.

Segundo Carbonell (2002, p. 20) a inovação educativa, em determinados contextos, associase à renovação pedagógica. Ele diferencia inovação de reforma, afirmando que tem a ver com a magnitude da mudança que se quer empreender. A mudança está voltada para o interior da escola, enquanto que a reforma diz respeito à estrutura do sistema educativo em seu conjunto, esta não é "[...] sinônimo de mudança, melhoria ou inovação. Estas podem provocá-la, mas também paralisála e sufoca-la".

O autor referido define inovação como um conjunto de,

[...] intervenções, decisões e processos, com certo grau de intencionalidade e sistematização, que tratam de modificar atitudes, ideias, culturas, conteúdos, modelos e práticas pedagógicas. E, por sua vez, introduzir, em linha renovadora, novos projetos e programas, materiais curriculares, estratégias de ensino e aprendizagem, modelos didáticos e outra forma de organizar e gerir o currículo, a escola e a dinâmica da classe (CARBONELL, 2002, p. 19).

Para Messina (2001, p. 226),

[...] de acordo com a literatura sobre o tema, podem-se identificar dois componentes que distinguem a inovação: a) a alteração, o de sentido a respeito da prática corrente e b) o caráter intencional, sistemático e planejado, em oposição às mudanças espontâneas. Também se enfatiza que atualmente a inovação é algo aberto, capaz de adotar múltiplas formas e significados, associados com o contexto no qual se insere.

Inovar é mudar? Transformar? Agir com criatividade? Adotar outra postura? O que realmente deve ocorrer de diferente na escola, na sala de aula, com o professor, com o processo de ensino e aprendizagem para podermos afirmar que há inovação? Inovação tem a ver com moda, modismos? Até que ponto o discurso da inovação traz algo de diferente e duradouro que se diferencia de outras ondas como a excelência na educação, a qualidade total ou o neotecnicismo? Parece que ainda não está muito claro isso para muitos educadores e gestores educacionais, cabe precisar melhor nosso entendimento sobre isso.

Inovação vem descrita na literatura contemporânea como toda e qualquer forma de pensar, criar e de usar nossos conhecimentos, métodos, técnicas e instrumentos que levem a práticas ou comportamentos diferenciados. Em meio às concepções que circulam, Carvalho $(2015$, p. 2) considera a inovação como o dar uma nova utilidade a instrumentos, ferramentas e objetos. Utilizar o conhecido para criar o desconhecido. "Uma nova visão ou um olhar diferente". Para o referido autor a inovação é aclamada sempre que há necessidade de mudar.

Rever, estudar e buscar outras possibilidades de ação para as mesmas dificuldades, até então insolúveis e aparentemente impossíveis de serem resolvidas. A identificação do processo de mudança é o primeiro passo para a inovação em 
qualquer área de conhecimento e segmento da realidade, em qualquer grupo de pessoas ou organização (CARVALHO, 2015, p. 2).

A inovação na educação, segundo o autor citado (2015, p. 100), preocupa-se em buscar soluções diversas e refletir sobre que possibilidades existem e quais podem ser consideradas para uma decisão efetiva nas didáticas, metodologias e novas estratégias para cada perfil de aluno. Neste contexto, "[...] as pessoas precisam 'inovar', sair do continuísmo, do instinto e do automático para refletir, questionar e buscar novas formas de pensar, agir e sonhar". Este sentido da inovação cabe muito bem à educação, pois nela há muitas práticas automatizadas, repetidas por costume ou acomodação, sem maior reflexão se ainda servem ou produzem resultados efetivos.

Guerra (2015) ao referir-se ao trabalho da escola e ao fazer do professor faz alusão às posturas conservadoras e às rotinas, dizendo que os professores recorrem a estas para enfrentar o planejamento. No seu entender é mais fácil repetir o que se está fazendo do que pensar se poderá ser feito de outro modo para fazê-lo melhor. Pondera sobre a possibilidade de não estarmos fazendo da melhor maneira ou até do jeito errado. Se estivermos errando ou não provocando aprendizagem é certo continuarmos? Repetimos rotinas convictos de que jamais erramos e que a forma como fazemos nosso trabalho não cabe reparos. Há certo dogmatismo, até prepotência ou autossuficiência docente. Para o autor, acima mencionado, a postura docente se ampara na ideia de que o que está sendo feito possui qualidade, ponto plenamente passível de questionamento.

Diriam que o critério mais definitivo de que as coisas estão sendo bem feitas é o de que estão fazendo-as como sempre fizeram. Parece que a repetição de costumes é a garantia de qualidade. No entanto, as exigências de mudança são tão urgentes e poderosas que quase sempre se chega tarde às novas necessidades e exigências (GUERRA, 2015, p. 86).

A necessidade de inovação surge como resposta natural a um cenário de mudanças e transformações constantes no conhecimento. $O$ caso da escola é peculiar e exemplar. Ela trabalha com o conhecimento, tem seu fazer relacionado a ele e não tem enfrentado dificuldades para acompanhar as vertiginosas mudanças na sociedade, ficando no descompasso com o que vem acontecendo. Acreditamos que o conceito emitido por Xavier (2013, p. 46) retrata muito bem a intencionalidade da inovação na educação.

[...] concebemo-la como um pensar criativo do sujeito que se materializa em um fazer eficaz. Diante de uma necessidade ou movido por uma inspiração, o sujeito consegue gerar a solução tão esperada ou antecipar a resposta a um problema por vir. A simples adaptação de um velho objeto ou a invenção totalmente inédita de um certo produto podem ser classificadas como inovação.

Nóvoa (1988, p. 8 apud COSTA, 2008, p. 72) defende que a inovação não pode ser vertical e precisa ser assumida de livre vontade para que ocorra como um empreendimento verdadeiro. Em outras palavras, inovar envolve mudar o comportamento das pessoas.

A inovação não se decreta. A inovação não se impõe. A inovação não é um produto. É um processo. Uma atitude. É uma maneira de ser e estar na educação que necessita de tempo, uma ação persistente e motivadora, requer esforço de reflexão 
e avaliação permanente, por parte dos diversos intervenientes do processo inovador.

Cardoso (1992 apud COSTA, 2008) considera a inovação como um conjunto de esforços isolados tendendo a melhorar ou mudar certos aspectos do processo educativo, significando uma ruptura com as práticas anteriores. A atribui-Ihe características essenciais:

a) traz algo de novo;

b) envolve mudança intencional e evidente;

c) exige um esforço deliberado e conscientemente adaptado;

d) supõe persistência da parte dos atores;

e) deseja o melhoramento da educação;

f) mobiliza o sujeito à avaliação;

g) provoca formação reflexiva - "investigação ação".

Cunha (2008) identifica características das experiências educativas inovadoras, são elas: ruptura com a forma tradicional de ensinar e aprender; gestão participativa; reconfiguração dos saberes; reorganização da relação teoria-prática; perspectiva orgânica no processo de concepção, desenvolvimento e avaliação da experiência desenvolvida; mediação e protagonismo.

Inovar está relacionado ao uso de novos artefatos ou recursos tecnológicos? À reestruturação dos espaços-tempos escolares? À outra dinâmica do fazer do professor? A um repensar da gestão educacional? O cerne da inovação tem a ver com o novo, pois as escolas estão repletas de "inovações pedagógicas", mas o novo não tem lugar. Para Imbernón (2012, p. 97) não basta focar no professor quando se pensa em inovação, há que se levar em consideração o meio onde o processo ocorre. "A inovação é uma mistura de formação e contexto. Para mudar a educação é preciso mudar o professorado e a formação contribui para isso, mas os modelos de organização e de gestão também precisam ser alterados".

\section{INOVAÇÃO PEDAGÓGICA: RUPTURA, MUDANÇA E POSSÍVEIS CAMINHOS}

Por mais que tenhamos dificuldades para definir com maior precisão o que a inovação envolve e exige, há uma certeza de fundo que demanda outras práticas: boa parte da escola do presente não atende às expectativas das famílias, do contexto social e às exigências do mundo do trabalho. Ela precisa ser repensada! Na visão de Tonucci (2015) a escola deve respostas às promessas constitucionais e às exigências de nossas sociedades atuais, modernas e democráticas, a escola deve ser capaz de realizar uma revolução interna, uma mudança radical que a converta em uma escola para todos os seus alunos e para cada um deles. "A escola deveria assumir como seu principal objetivo o de ajudar cada um de seus discípulos a descobrir qual é seu campo de excelência e a trabalhar para Ihe dar valor. Sobre essa excelência poderá construir seu futuro, seu trabalho, sua felicidade" (TONUCCI, 2015, p. 69).

Uma escola inovadora deve carregar consigo a perspectiva de vanguarda, pensar-se no presente antevendo ou prospectando possibilidades. Não se trata de querer fazer apologias ou adivinhações, mas pensar estrategicamente e agir com rumo definido, pois, aqui cabe muito bem a máxima de que quem não sabe para onde vai todos os caminhos levam a lugar nenhum. "Não se 
trata, portanto, de pensar o futuro, nem muito menos de prevê-lo, mas de pensar no futuro, o que é algo muito diferente" (ECHEVERRÍA, 2015, p. 38).

O futuro esperado ou diferente só será possível se for gestado de forma diferente no presente. Fazendo do mesmo modo que fazemos as coisas não podemos esperar muita coisa a não ser a repetição ou reprodução. Uma prática nova ou ainda não experimentada começa com a mudança na sua concepção, em outras palavras, sua gênese está no pensamento criativo que a possibilita. De acordo com Messina (2007), mudar implica desnaturalizar ou distanciarmo-nos do habitus que nos constitui, que é tão estruturante quanto estruturado, separarmo-nos desses modos de sentir, pensar e agir. Mudar altera a regra, o regime ou o modo como organizamos nossas vidas. $E$ isto exige de nós uma compreensão de futuro como tempo newtoniano, como possibilidade. Segundo Sacristán (2015, p. 12), o futuro como lugar ou espaço do tempo não existe no presente, mas é no presente que somos chamados a intervir para condicioná-lo. Não se trata de um tempo vivido, pois seria passado. O futuro nós o fazemos agora. "Educa-se para o futuro educando no e para o presente".

Inovar tem estreita vinculação com pensar no devir, no vir-a-ser, no que ainda não é, mas possui potencialidade para tornar-se. Esta capacidade de vir-a-ser algo que ainda não é ou de fazer algo que difere do que é feito agora, está na essência do aprender e do ser humano, como construtor de si mesmo.

O futuro também é o tempo em que situamos os projetos, os desejos, as aspirações de uma vida melhor e também a libertação dos males que nos oprimem no presente. O futuro é o tempo de redenção, de plenitude, mas também dos temores, de incertezas mais ou menos racionais ou doentias (SACRISTÁN, 2015, p.14).

Imbuídos deste espírito, propomo-nos um exercício de pensar em algumas características que estariam presentes em escolas ou práticas pedagógicas inovadoras, que em escala maior culminariam em uma educação inovadora. Sabemos que corremos o risco de deixar algumas de fora ou secundarizá-las, contudo, preferimos arriscarmos a pecar pela omissão ou falta de coragem. Assim destacamos e problematizamos brevemente algumas delas. Desta forma uma escola inovadora:

\subsection{Forma para além do espaço da fábrica²}

Para outras organizações intermediadas pela tecnologia, em outras palavras "hoje já e no futuro o posto de trabalho será outro". Inovação tem que ser pensada na relação com o trabalho ou com possíveis ocupações em que as pessoas estarão no seu futuro, seja ele próximo ou distante. A escola não pode furtar-se a esta tarefa, pois isto diz respeito à sua função social e de cidadania. $E$ a pergunta que precisa ser feita é onde estarão os postos de trabalho? Quais os setores da economia que vão absorver pessoas? Na economia do conhecimento a escola deve preparar para qual tipo de trabalho? Echeverría (2015, p. 42) sinaliza por onde a escola deve seguir.

\footnotetext{
${ }^{2}$ A escola e a organização da sala de aula que possuímos ainda hoje apresentam características de uma educação influenciada ou voltada para o modelo fabril: alunos divididos em classes ou turmas, conteúdos curriculares compartimentados ou em disciplinas, períodos tempo estratificado em períodos. A escola deve "disciplinar" ou preparar o trabalhador para que se adapte ao processo produtivo.
} 
A escola do futuro não formará pessoas para trabalhar nas indústrias, salvo uma parte, mas sim em setores relacionados à informação e ao conhecimento, isso porque também o trabalho será realizado cada vez mais no terceiro setor, como vem ocorrendo desde a última década.

Enquanto que na lógica do mercado a inovação adquire caráter de oportunidade ou possibilidade em função de um poder de compra ou aquisição de um bem, produto ou serviço, na educação, a inovação possui vínculos diretos com o direito a ser educado e a ter uma educação de qualidade, portadora de requisitos que permitam aos indivíduos enfrentarem o mundo vivido em cada circunstância. Em outras palavras, ter acesso e garantia a uma educação inovadora constituise em direito do ser humano não uma concessão; ela não poder ser regrada pela lógica do mundo produtivo, necessita estar na esfera do direito público.

\subsection{Trabalha com outra forma de organização}

A mediação tecnológica está presente, com outras posturas do professor e formas diferentes de tratar o conhecimento. Ou seja, "Nos processos de aprendizagem, será preciso adquirir uma série de conhecimentos, ter certas capacidades e desenvolver determinadas habilidades e aptidões" (ECHEVERRÍA, 2015, p. 45). Ao entender a inovação enquanto uso de novas tecnologias digitais, devemos estar atentos para evitar os discursos salvacionistas ou messiânicos, pois para Candido (2014), inovar na educação não é sinônimo de colocar computadores, lousas digitais e toda a parafernália tecnológica nas salas de aula e escolas. Inclusão digital no contexto da inovação é apenas um detalhe.

Acreditamos que a inovação possui estreita relação com as tecnologias digitais da informação e comunicação. A inovação tecnológica é uma forma poderosa de inovação pois não são" [...] simples ferramentas que ajudam a fazer estas ou aquelas coisas, senão que constituem mediações autênticas dessas ações, razões pela qual não seriam factíveis sem elas" (ECHEVERRÍA, 2015 , p. 43). Por isso só elas representam parte do que entendemos por inovação, mas seu uso adequado e com finalidade definida podem tornar-se ferramentas com finalidade social, integrantes do que podemos chamar de inteligência coletiva. Elas não apenas democratizam os processos de informação e comunicação entre as pessoas, mas acima de tudo reconfiguram "[...] as relações e as ações humanas, tanto individuais quanto coletivas e institucionais" (ECHEVERRÍA, 2015, p.43).

\subsection{Possui energia criativa para enfrentar a complexidade}

Ou seja, enfrentar as mudanças permanentes no cenário em que vivemos, em que é preciso pensar e fazer uso do pensamento criador. Para Costa (2008, p. 77), em síntese, inovar é uma necessidade e um imperativo, mas a condução do seu processo terá de ser mais participativo e flexível, "[...] dando relevância às estratégias de inovação, que permitam a organização transformarse numa organização aprendente. É necessário que todos os professores se sintam membros dessa organização que está em constante aprendizagem".

No pensar de Messina (2007) nos últimos dez anos, estabeleceu-se uma relação direta entre mudanças na educação e sociedade globalizada. A bibliografia sobre o tema destaca que a globalização econômica, social, política e cultural exige sistemas flexíveis e abertos às mudanças. 
Em resumo, fala-se de sociedades em processo acelerado de mudança e que necessitam de sistemas educacionais compatíveis.

\subsection{Tem capacidade de inovar}

Capacidade de romper com a visão dogmática do conhecimento, concebe-o dentro da perspectiva da incerteza, dinâmico, novo. Tem estreita vinculação com correr riscos, com romper com o imaginário de segurança. Para Candido (2014, p. 2) "[...] a ousadia e a coragem em correr riscos passam a ser características importantes dos que se envolvem no processo educacional; errar, acertar e principalmente acreditar que o experimento é parte de um processo de aprendizagem dessa nova educação".

Para Leite, Genro, Braga (2011, p. 25-26) a inovação pedagógica vem para alterar uma certeza, produzir dúvidas, gerar inquietação, para ajudar a pensar diferente o modo considerado normal, para ativar outras zonas do cérebro que não aquelas do cominho neural preferencial. "A inovação pedagógica está para desestabilizar o pensar reprodutivo e instalar em seu lugar a inquietação, a ansiedade pelo saber mais, pelo entender o que não se entende, por compreender pontos de vista que à primeira vista podem parecer distanciados entre si".

Não defrontar-se com o risco ou fugir dele pode ser uma das posturas que os docentes adotam para não aderir à mudança. Desenvolver uma cultura que estimule os docentes a correr riscos torna-se parte fundamental de uma escola bem sucedida. Segundo Cunha (2008), o incentivo ao risco pressupõe, entretanto, uma ambiência institucional que o tolere e, inclusive estimule-o.

\section{5 É plena quando todos os professores forem atores}

É preciso revisitar a qualificação e formação verdadeira que supera o "faz de conta" dos cursos, conferências, para transformar tudo isso em práticas de profundo estudo e reflexão sobre a docência. Quem está propondo a inovação? Sob que perspectiva? Messina (2001) alerta que em um mundo tão globalizado como fragmentário, a inovação educacional é atualmente uma estratégia que parte do centro, portanto, um mecanismo a mais de regulação social e pedagógica. "Também opera como um mecanismo de recentralização e de homogeneização. Ao transformar-se em uma das estratégias preferenciais das reformas, a inovação foi ela mesma 'reformada'" (MESSINA, 2001, p. 228).

As experiências mais bem-sucedidas de inovação educacional consideram e dão importância aos educadores como atores no processo de mudança. Eles devem ser valorizados e ouvidos, podendo exercer sua capacidade de decisão e de escolha nos processos. Não há mudança verdadeira sem a participação dos professores. Quando forem deixados à margem, ignorados em suas necessidades, desconsiderados em suas formas de pensar e experiência, as propostas terão maior probabilidade de fracassar.

Igualmente se propõem três ações centrais em relação aos educadores: a) que expressem e escutem sua voz interior; b) que realizem a reflexão na ação (na, sobre e para a ação) e c) que desenvolvam uma mentalidade para assumir riscos. Isso implica combinar o tempo de trabalho em grupo com o tempo de trabalho individual, mantendo a coragem com o compromisso de reflexão (MESSINA, 2007, p. 231). 
Leite, Genro, Braga (2011) trazem outros elementos para somar-se aos apontados que sustentam a inovação pedagógica. Fatores que aceleram os processos pedagógicos inovadores tais como o protagonismo dos sujeitos, a partilha de poderes e saberes em situações de ensinoaprendizagem, o respeito e a descoberta, tanto por parte dos professores quanto dos alunos, dos pressupostos filosóficos e ontológicos que presidem o conhecer.

\subsection{Está propensa à mudança de método}

Ruptura também serve de referência para falar de inovação, especialmente quando se trata de conhecimento. Seu uso diferenciado ou sob outro paradigma, supera o caráter de "mera novidade". "A inovação existe em determinado lugar, tempo e circunstância, como produto de uma ação humana sobre o ambiente ou meio social" (CUNHA, 2008, p. 24).

No entendimento de Leite, Genro, Braga (2011, p. 25) ao falar em inovação pedagógica referimo-nos à construção de espaços não-reguladores em aprendizagem, a tensões e contradições nos discursos, a campos epistemológicos subjetivos que favorecem transformações porque introduzem a dúvida e as interrogações sobre certezas historicamente fundadas. "Referimo-nos a extrapolação de paradigmas vigentes que reificam a acumulação de conhecimento, reificam uma forma preponderante e hegemônica de produzir conhecimento e ensinar conteúdos".

\subsection{O conhecimento da neurociência para ensinar e fazer aprender melhor}

Os estudos relacionados à neurociência produziram um corpo de conhecimentos bastante extenso, no entanto há poucas ligações com as políticas e práticas educativas, o que nos remete a sugerir a busca destes saberes, sua transposição ou interfaces com a educação. Segundo Blakemore e Frith (2009), só compreendendo como o cérebro adquire e consolida informações e competências poderemos alcançar os limites da sua capacidade de aprender.

Nos cursos de formação de professores estes conhecimentos estão praticamente ausentes e uma educação que se quer inovadora não pode abrir mão das possibilidades que estes oferecem aos educadores de melhorarem seus métodos e aprimorem suas estratégias de aprendizagem pela aquisição e utilização dos saberes advindos da neurociência. De acordo com Oliveira (2014) concebendo o neurodesenvolvimento, o educador pode fazer maior uso das teorias e práticas educacionais levando em conta a base biológica e os mecanismos neurofuncionais que lhe permitem otimizar as capacidades do aluno.

Perceba-se que há todo um potencial a ser explorado por parte dos educadores e dos gestores de políticas educacionais quanto ao uso dos conhecimentos da neurociência de forma interdisciplinar com a educação. Este talvez seja uma dos ganhos mais significativos em termos de subsídios para que se possa estabelecer a diferença entre uma escola que só ensine para uma escola que também faça com que os estudantes aprendam.

\subsection{Prepara a mente aberta e ética para viver na sociedade pluralista}

É preciso dialogar com as novas configurações de família, casamentos, opções sexuais respeitando o ser humano e reconhecendo sua dignidade e seu valor. Ensinar para a ética e a diversidade, convívio global e defesa da biodiversidade como condição de sustentabilidade da 
humanidade sobre a terra. Disciplinar-se para enfrentar o consumismo e não para por em risco a vida humana sobre o planeta. Estimular a sensibilização ecológica planetária.

A inovação remete a questionar as racionalidades fundantes das compreensões de mundo, a repensar a racionalidade instrumental que prioriza o produto, o lucrativo e o econômico em detrimento do humano. No pensar de Messina (2001) a orientação que compele à mudança, o deslumbramento por qualquer coisa que seja nova e moderna são movimentos nos quais se perde o sentido da educação como renascimento. As inovações educacionais que seguem a lógica entre o custo e o benefício são uma expressão da racionalidade instrumental, com seu correlato de descuido e destruição.

\subsection{Educa para a autonomia e a responsabilidade}

Quando estudamos ou tratamos da mudança é importante não perder de vista a resistência à mudança ou à inovação. O ser humano e, por decorrência, as organizações por ele criadas refletem um comportamento muito comum: a resistência ao novo. Dispendia-se muitas energias e trabalho para que as coisas fiquem do jeito que estão ou para que se mantenha a rotina.

A estrutura ou organização do sistema educacional pode provocar ou impedir a inovação. A burocracia, as normas, a centralização administrativa, a pouca democracia reduzem a autonomia e cristalizam o status quo, impedindo reações que provocam ações ou atitudes criativas e inovadoras, havendo assim correlação direta entre o contexto das relações de poder na escola e o aparecimento de práticas inovadoras. Quanto mais vertical e centralizada for a gestão, menor a possibilidade de surgir o novo.

Na perspectiva de Messina (2001, p. 227) as classificações a respeito da inovação contam muito pouco, o que interessa é o seu sentido e finalidade. Elas foram classificadas em pedagógicas ou institucionais, em micro e macro, impostas ou voluntárias. Entretanto, a diferença que conta é aquela relacionada com o sentido, "[...] se por acaso a inovação torna possível que os sujeitos e as instituições sejam mais donos de si, mais plenos e autônomos em sua maneira de ser, fazer e pensar ou, ao contrário, os submete a uma lógica nica, aceita como natural".

A OCDE (1973 apud COSTA 2008) aponta que as escolas mais inovadoras são as que possuem mais capacidade em resolver problemas, maior abertura com a comunidade, disponibilidade para a discussão dos problemas e fluidez das comunicações. Os docentes revelam uma atitude de cooperação entre os seus membros, que permite a crítica construtiva e a interajuda. Todas elas apresentavam um elevado grau de autonomia e os seus líderes desempenham um papel ativo na busca de informações e conhecimentos referentes às atividades inovadoras. Os conflitos são vistos como potencializadores da mudança, uma decorrência natural do processo de inovação.

\subsection{Ancora sua ação e atua com base no planejamento}

A ausência de planejamento e o pouco interesse em querer desacomodar-se geram aplicação de rotinas baseadas naquilo que sempre se fez, o quem gera críticas não somente dos estudantes, mas também de pais e estudiosos da educação. A reflexão sobre a prática provoca a necessidade de mudança, desestabiliza, tira do lugar, talvez por isso que muitos educadores 
empenham pouco ou nenhum esforço no exercício de pensar sobre o que fazem, como fazem e porque fazem.

Segundo Leite, Genro, Braga (2011) o caráter pedagógico de uma inovação está na sua capacidade de mobilizar, reconstruir, reorganizar a realidade. Ela produz efeitos e rearranjos entre os saberes e os poderes.

Uma inovação é pedagógica porque reconfigura ou favorece disputa entre saberes e poderes na sala de aula, porque convive e dá guarida às descontinuidades e incertezas do conhecimento, porque entra em conflito com os paradigmas tradicionais e acolhe o pensar e o fazer democrático (LEITE; GENRO; BRAGA, 2011, p. 38).

O planejamento é um ato reflexivo, contínuo e dinâmico. Demonstra nossa capacidade e entendimento a respeito dos objetivos a que nos propomos. Sua natureza revela o caráter decisório, político de nossas intenções, de nossas escolhas teóricas e metodológicas, por isso precisa estar carregado de sentido e de convicção de onde estamos para onde queremos ir, portanto não pode ser fruto do improviso ou da casualidade. Resulta do pensado, da definição de estratégias e das finalidades a que nos propomos.

\subsection{Reconhece e valoriza as emoções}

Compreende seu papel nos processos de ensinar-aprender e seu lugar no todo do ser humano. A tradição da escola está centrada no entendimento da razão como prioritária nos processos de conhecimento. Somos frutos do cartesianismo e procedemos na educação segundo seus princípios. No entanto, os estudos recentes das Ciências Cognitivas apontam para a importância das emoções, sua função e relação como a aquisição de conhecimento e os mecanismos de aprendizagem. Não podemos conhecer sem a presença das emoções.

Este novo entendimento a respeito do lugar e papel das emoções não significa que devamos desconsiderar a razão, mas torna-se fundamental rever nossos conceitos e conceber a razão e as emoções em um patamar de maior equilíbrio. O fiel da balança tem pendido mais para a razão ao longo da história da escolarização, faz-se urgente rever isto. As pesquisas atuais demonstram que as emoções devem ser consideradas. Hoje, possuímos conhecimento e estudos bem fundamentados a despeito da relevância das emoções para o ser humano, o que nos permite pensar sobre elas com mais segurança e com maior confiabilidade.

Na compreensão de Mora (2012), as emoções despertam e mantém tanto a curiosidade quanto a atenção, assim como o interesse pela descoberta de tudo o que é novo, desde um alimento ou um inimigo até as aprendizagens em sala de aula. As emoções, em última análise, são a base na qual se assentam todos os processos de aprendizagem e memória.

\section{CONSIDERAÇÕES FINAIS}

Ao finalizar as reflexões do artigo, consideramos relevante elencar alguns pontos-sínteses pertinentes que nos possibilitam analisar e perceber a contribuição da inovação para a prática 
pedagógica e para o contexto educacional brasileiro. Concomitantemente, a inovação contribui para:

- Possibilitar uma educação criativa. Onde seja possível desenvolver um processo educativo que desenvolva e aprimore a capacidade criativa no contexto socioeducacional brasileiro. Mas para que isso seja efetivo, precisamos encontrar estratégias cognitivas, novas formas de pensar e de motivar os estudantes para novas experiências, para ousarem, alimentarem a confiança em si próprios, superarem seus medos, arriscarem-se. Desta forma poderão desenvolver todas as suas capacidades, tornando-as elementos essenciais para a prática da inovação.

- Repensar os valores e a democracia. É através desta via que poderemos fortalecer a necessidade de termos sociedades justas e democráticas, ou seja, através da participação dos movimentos e grupos sociais, poderemos integrar, valorizar e preservar os saberes e conhecimentos de cada população. A inovação não deve satisfazer uma minoria, deve ser democrática, com uma perspectiva essencialmente social e não comercial. À inovação cabe implementar a noção de prática social, incluindo representações, grupos, conhecimentos, sempre através de práticas realizadas no coletivo. A inovação com o coletivo apresenta maior capacidade de integrar, de organizar regras, assumir transparência, cooperação e reconhecimento de necessidades por meio de uma construção política, para um bem comum. Sem este propósito, a sociedade poderia se desagregar, descontextualizar com o compromisso das práticas sociais. Ou seja, precisamos de uma inovação que inclua ao invés de excluir, que amplie o conhecimento através da integração (uma vez que não poderemos usar a palavra diálogo).

- Reunir esforços para conservar e valorizar o patrimônio cultural, pois a inovação sem memória, sem resgate, se tornará vazia, é preciso cultivar e manter os costumes, as tradições e a história de cada sociedade. "Cada innovación depende Del cambio que se há venido gestando en El marco de uma determinada cultura tecnológica. Artística, cientifica, filosófica u organizativa". Necessitamos de uma escola que utilize o patrimônio cultural para divulgar inovadoras cumprindo sua função de ensinar, assim procedendo-os do ponto de vista pessoal e profissional.

- Mudar mentalidades, práticas, fundamentos teórico-metodológicos, formas de pensar e conduzir os processos pedagógicos. Trabalhar para que seja instalada uma "cultura da inovação" na escola e na educação. É preciso compreender como e aonde as mudanças irão se processar e quem será afetado por ela. A inovação não pode ser reduzida ao desenvolvimento tecnológico, pois a tecnologia deverá transformar a criatividade e as ideias em realidade. A inovação faz parte de uma rede, de uma integração em que os compromissos determinados pelo todo sejam assumidos com intervenções concretas dentro de um plano sistemático de gestão.

- Instituir um novo dinamismo no campo da educação, caracterizado ou materializado por outro momento histórico que vivemos, principalmente pelo reconhecimento dos saberes, das práticas e das teorias existentes em função da configuração do conhecimento no século 21 . A complexidade e a dinâmica do conhecimento de nosso século demandam que o professor seja agente dinamizador e mediador para novas aprendizagens, abrindo espaço para uma educação que prepare o ser humano para ser ator nesse processo. Requer pensar percursos e estratégias de aprendizagem condizentes com o contexto social e tecnológico em que vivemos.

- Conceber a inovação como um processo de evolução humana. Serĺamos nós os protagnistas de uma constante inovação? Segundo os últimos escritos de Freire (2000, p. 16), não “[...] haveria 
cultura nem história sem inovação, sem criatividade, sem curiosidade, sem liberdade sendo exercida ou sem liberdade pela qual, sendo negada, se luta". E nós enquanto educadores, temos liberdade e responsabilidade para escolher ou aceitar o novo? Em resposta a essa questão, o autor citado justifica: "Estou convencido de que a primeira condição para aceitar ou recusar esta ou aquela mudança que se anuncia é estar aberto à novidade, ao diferente, à inovação, à dúvida" (2000, p.19). Concordamos com ele de que é preciso estar aberto e atento a toda e qualquer outra possibilidade criadora. No entanto, pensar sobre o que a inovação poderá implicar ou gerar na escola, na prática pedagógica e nas sociedades, é fundamental.

\section{REFERÊNCIAS}

1. BLAKEMORE, S. e FRITH, U. O cérebro que aprende: lições para a educação. Portugal: Gradativa, 2009.

2. CANDIDO, J. P. Inovação na educação. Viva S/A. X São Paulo: Projeto Editora, ano 12, edição 152, jan, 2014.

3. CARBONELL, J. A aventura de inovar: a mudança na escola. Porto Alegre: Artmed, 2002.

4. CARDOSO, A. P. Educação e inovação. Millenium, no 6, março de 2007. Disponível em: http://www.ipv.pt/millenium/Millenium_6.htm Acessado em janeiro de 2015.

5. CARVALHO, M. B. de A inovação tecnológica em educação e saúde: um caminho promissor. Disponível em: www.telessaude.uerj.br/resource/goldbook/pdf/41.pdf Acessado em 2015.

6. COSTA, M. da L. V. F. A promoção da inovação e mudança nas escolas de 1o Ciclo em agrupamento, no Coelho de Lourdes. Dissertação de Mestrado, 2008. Disponível em: https://repositorioaberto.uab.pt/.../1/Microsoft\%20Word\%20-\%20Mestra... Acessado em 2015.

7. CUNHA, M. I. da Inovações pedagógicas: o desafio da reconfiguração de saberes na docência universitária. Cadernos de Pedagogia Universitária, número 6. São Paulo: USP, 2008.

8. ECHEVERRÍA, J. A escola contínua e o trabalho no espaço-tempo eletrônico. In: INBERNÓN, F. e JARANTA, B. Pensando o futuro da educação: uma escola para o século XXII. Porto Alegre: Penso, 2015.

9. FREIRE, Paulo. Pedagogia da Indignação. São Paulo: Unesp, 2000.

10. GUERRA, M. A. S. Adiantar-se ao futuro: agrupamentos de alunos. In: INBERNÓN, F. e JARANTA, B. Pensando o futuro da educação: uma escola para o século XXII. Porto Alegre: Penso, 2015.

11. IMBERNÓN, F. Inovar o ensino e a aprendizagem na universidade. São Paulo: Cortez, 2012.

12. LEITE, D.; GENRO, M. E. H.; BRAGA, A. M. e S. Inovações pedagógicas e demandas ao docente na universidade. In: Inovação e pedagogia universitária. Porto Alegre: UFRGS, 2011.

13. MESSINA, G. Mudança e inovação educacional: notas para reflexão. Cadernos de Pesquisa. São Paulo: Fundação Carlos Chagas, no 114, novembro de 2001.

14. MORA, F. Neuroeducação para ensinar e aprender melhor. Revista Pedagógica Pátio. Porto Alegre: Artmed, ano XVI, no 61, Fev./Abril 2012.

15. MORALES, A. C. Innovación social: un ámbito de interés para los servicios sociales, 
Zerbit- zuan, núm.

45,2009.

disponible

en:

http://www.zerbitzuan.net/documentos/zerbitzuan/12 .pdf

16. OLIVEIRA, G. G de Neurociências e os processos educativos: um saber necessário na formação de professores. Educação. São Leopoldo: Unisinos, 18 (1), jan./abril de 2014.

17. SACRISTÁN, J. G. Apresentação. Por que nos importamos com a educação no futuro. In: INBERNÓN, F. e JARANTA, B. Pensando o futuro da educação: uma escola para o século XXII. Porto Alegre: Penso, 2015.

18. SAVIANI, D. A Filosofia da Educação e o problema da inovação em educação. In: GARCIA, W.E. (Org.) Inovação educacional no Brasil. S. Paulo: Cortez, 1980.

19. TONUCCI, F. Os alunos na escola do amanhã. In: INBERNÓN, F. e JARANTA, B. Pensando o futuro da educação: uma escola para o século XXII. Porto Alegre: Penso, 2015.

20. XAVIER, A. C. Educação, tecnologia e inovação: o desafio da aprendizagem hipertextualizada na escola contemporânea. Revista (Con) Textos Linguísticos - Edição especial ABEHTE. Espírito Santo: UFES, v. 7, no 8.1, 2013. 